\title{
Pretreatment thrombocytosis as an independent predictive factor for chemoresistance and poor survival in epithelial ovarian cancer
}

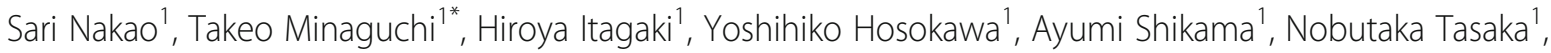 \\ Azusa Akiyama ${ }^{1}$, Hiroyuki Ochi ${ }^{1}$, Koji Matsumoto ${ }^{2}$ and Toyomi Satoh ${ }^{1}$
}

\begin{abstract}
Background: Thrombocytosis is related to tumor stage and survival in ovarian cancer in addition to the common complications of malignant diseases, such as anemia and inflammation. The aim of our study was to clarify the precise prognostic impact of pretreatment thrombocytosis in epithelial ovarian cancer.

Methods: We retrospectively analyzed 280 consecutive patients who were treated for epithelial ovarian cancer at our institution between 2001 and 2011.

Results: Pretreatment thrombocytosis was observed in $18.9 \%$ of all patients and was associated with advanced FIGO stage, primary treatment, operation achievement, histologic subtype, microcytic hypochromic anemia (MHA), and nonmalignant inflammatory condition $(P=0.0018,0.0028,0.00050,0.034,0.00090$ and 0.0022$)$. In the patients who relapsed after primary adjuvant chemotherapy $(n=126)$, thrombocytosis was associated with a shorter treatment-free interval (TFI) $(P=0.0091)$. The univariate and multivariate analyses revealed that thrombocytosis was independently associated with TFI and MHA ( $P=0.021$ and 0.0091). Patients with thrombocytosis had worse progression-free survival (PFS) and overall survival (OS) than those without thrombocytosis $(P<0.0001$ and $<0.0001)$. The multivariate analyses for prognostic factors demonstrated that thrombocytosis was significant for poor PFS and OS ( $P=0.0050$ and 0.022$)$ independent of stage, histology, primary treatment, operation achievement, nonmalignant inflammatory condition and MHA.

Conclusions: The current findings indicate that the detrimental survival impact of pretreatment thrombocytosis in epithelial ovarian cancer may be independent of tumor extent but rather attributed to chemoresistance, further supporting the therapeutic potential of targeting thrombopoietic cytokines in the disease.
\end{abstract}

Keywords: Thrombocytosis, Ovarian cancer, Survival

\section{Background}

Approximately half of all patients with ovarian cancer are diagnosed with advanced-stage disease [1], as early-

\footnotetext{
* Correspondence: minaguchit@md.tsukuba.ac.jp

'Department of Obstetrics and Gynecology, Faculty of Medicine, University of Tsukuba, 1-1-1 Tennoudai, Tsukuba, Ibaraki 305-8575, Japan

Full list of author information is available at the end of the article
}

stage patients tend to rarely have subjective symptoms due to the anatomical location of the ovary as an intraperitoneal organ. The principal treatment for epithelial ovarian cancer is maximal cytoreduction, which typically comprises surgery followed by chemotherapy, and the amount of residual tumor is one of the most important prognostic factors [2-5]. Accordingly, the elucidation of

(c) The Author(s). 2020 Open Access This article is licensed under a Creative Commons Attribution 4.0 International License, which permits use, sharing, adaptation, distribution and reproduction in any medium or format, as long as you give appropriate credit to the original author(s) and the source, provide a link to the Creative Commons licence, and indicate if changes were made. The images or other third party material in this article are included in the article's Creative Commons licence, unless indicated otherwise in a credit line to the material. If material is not included in the article's Creative Commons licence and your intended use is not permitted by statutory regulation or exceeds the permitted use, you will need to obtain permission directly from the copyright holder. To view a copy of this licence, visit http://creativecommons.org/licenses/by/4.0/ The Creative Commons Public Domain Dedication waiver (http://creativecommons.org/publicdomain/zero/1.0/) applies to the data made available in this article, unless otherwise stated in a credit line to the data. 
mechanisms for tumor growth and metastasis will contribute to improving patient prognosis. Thrombocytosis is traditionally known to be associated with patient prognosis in ovarian cancer [6-15]. Platelets are involved in tumor growth, angiogenesis, and metastasis [16]. The functions of cytokines on platelet-mediated tumor proliferation and progression have been widely investigated [16]. Recently, antiplatelet therapies including molecular agents targeting thrombopoietic cytokines have been investigated by clinical trials in patients with ovarian cancer $[17,18]$. However, the precise prognostic significance of paraneoplastic thrombocytosis is yet to be determined. Thrombocytosis is known to be induced by irondeficiency anemia and nonmalignant inflammatory conditions in addition to malignant disease, and ovarian cancer patients, especially those with advanced-stage disease, may have these complications. The aim of our study was to investigate the detailed prognostic impact of thrombocytosis on ovarian cancer patients in order to elucidate the underlying mechanism and to identify the target patients who will benefit more from antiplatelet therapies.

\section{Methods}

\section{Patients}

We retrospectively reviewed the clinical records of a total of 280 consecutive patients who were treated for epithelial ovarian cancer at the University of Tsukuba Hospital between 2001 and 2011. The study protocol was approved by the Ethics Committee University of Tsukuba Hospital (H27-143). We excluded patients with multiple primary cancers, a past history of cancer, or hepatic disease from our study. Patients diagnosed with malignant transformation of mature cystic teratoma were also excluded. Thrombocytosis was defined as a platelet count $\geq 400,000 / \mathrm{mm}^{3}$ before treatment, which was calculated as the mean value of the initial and pretreatment examinations. For survival analyses, progression-free survival (PFS) was defined as the interval between the dates of the initial treatment and the first recurrence or progression of disease, and overall survival (OS) was defined as the interval between the dates of the initial treatment and the last follow-up. The treatment-free interval (TFI) was defined as the interval between the dates of the end of primary adjuvant chemotherapy and the first disease progression $(n=126)$. The stages were classified according to the International Federation of Gynecology and Obstetrics system (FIGO, 1988). The median follow-up period excluding patients who died was 81.4 months (range, $0.7-178$ ). The patient demographics are summarized in Table 1.

\section{Treatment}

The basic surgical procedure for epithelial ovarian cancer consisted of total abdominal hysterectomy, bilateral
Table 1 Patient characteristics.

\begin{tabular}{|c|c|c|}
\hline Characteristics & & No. $(n=280)$ \\
\hline Age (years) & Mean \pm SD & $56.7 \pm 11.9$ \\
\hline \multicolumn{3}{|c|}{ Platelet counts $\left(\times 10^{3} / \mathrm{mm}^{3}\right)$} \\
\hline$\geq 400$ & & $53(18.9 \%)$ \\
\hline$<400$ & & $227(81.1 \%)$ \\
\hline $\mathrm{Hb}(\mathrm{g} / \mathrm{dl})$ & Mean \pm SD & $11.8 \pm 1.5$ \\
\hline \multicolumn{3}{|c|}{ Microcytic hypochromic anemia } \\
\hline Present & & $23(8.2 \%)$ \\
\hline Absent & & $259(91.8 \%)$ \\
\hline \multicolumn{3}{|c|}{ Primary treatment } \\
\hline PDS & & $207(73.9 \%)$ \\
\hline NAC & & $73(26.1 \%)$ \\
\hline \multicolumn{3}{|l|}{ FIGO stage } \\
\hline I & & $91(32.5 \%)$ \\
\hline$\|$ & & $39(13.9 \%)$ \\
\hline III & & $110(39.3 \%)$ \\
\hline IV & & $40(14.3 \%)$ \\
\hline \multicolumn{3}{|c|}{ Histologic subtype } \\
\hline Serous & & $105(37.5 \%)$ \\
\hline Clear cell & & $83(29.6 \%)$ \\
\hline Others* & & $92(32.9 \%)$ \\
\hline \multicolumn{3}{|c|}{ Operation achievement } \\
\hline Complete & & $206(73.6 \%)$ \\
\hline Optimal & & $56(20.0 \%)$ \\
\hline Suboptimal & & $18(6.4 \%)$ \\
\hline \multicolumn{3}{|c|}{ Nonmalignant inflammatory condition } \\
\hline Present & & $15(5.4 \%)$ \\
\hline Absent & & $265(94.6 \%)$ \\
\hline CA125 (U/ mL) & Mean \pm SD & $1591 \pm 3618$ \\
\hline
\end{tabular}

*Endometrioid, mucinous, undifferentiated, or mixed type. Abbreviations: $S D$ standard deviation, $\mathrm{Hb}$ hemoglobin, PDS primary debulking surgery, NAC neoadjuvant chemotherapy, FIGO International Federation of Gynecology and Obstetrics

salpingo-oophorectomy, omentectomy, and pelvic and para-aortic lymphadenectomy. Following primary debulking surgery (PDS), a combination of paclitaxel $\left(175 \mathrm{mg} / \mathrm{m}^{2}\right.$, day 1$)$ and carboplatin $(\mathrm{AUC}=6$, day 1$)$ (TC regimen) was administered every 3 weeks. Four cycles of TC were performed in patients with stage IA clear cell carcinoma. Six to 8 cycles were performed in patients with stage IC or higher disease. Neoadjuvant chemotherapy (NAC) followed by interval debulking surgery (IDS) was selected for patients with apparent stage III/IV disease and chemosensitive tumor histology, i.e., serous or endometrioid as estimated by CT, excessively elevated CA125 levels, and cytological findings of ascites [19]. For NAC, 4 cycles of TC were administered, and IDS was followed by an additional 4 cycles. 


\section{Statistical analysis}

Differences in proportions were evaluated by the $x^{2}$ test or Fisher's exact test where appropriate. Differences in continuous variables were evaluated by the Wilcoxon rank-sum test. Logistic regression was used for the univariate and multivariate analyses of the clinicopathologic factors associated with thrombocytosis. Kaplan-Meier survival curves were generated and compared statistically by the log-rank test. The Cox proportional hazard model was used for the univariate and multivariate analyses for prognostic factors. $P$-values $<0.05$ were considered statistically significant. All statistical analyses were performed using JMP11.0 software (SAS Institute, Cary, $\mathrm{NC}$ ).

\section{Results}

Thrombocytosis was observed in $18.9 \%$ of all patients (Table 1). We first examined the relationships between thrombocytosis and the clinicopathologic parameters.
The rate of thrombocytosis significantly increased as the FIGO stage progressed: the rate was $9.9 \%$ (9/91) for stage I, $10.3 \%(4 / 39)$ for stage II, $23.6 \%(26 / 110)$ for stage III, and $35.0 \%$ (14/40) for stage IV (Table 2). Additionally, thrombocytosis was found to be significantly associated with microcytic hypochromic anemia (MHA), primary treatment (NAC vs. PDS), histologic subtype (serous, clear cell, or others), operation achievement (complete, optimal, or suboptimal resection), nonmalignant inflammatory condition, and CA125 level (Table 2).

We subsequently conducted univariate and multivariate analyses of the clinicopathologic factors associated with thrombocytosis. Among the factors significantly associated with thrombocytosis in Table 2, we selected MHA, FIGO stage, histologic subtype, operation achievement, and nonmalignant inflammatory condition as the factors to be analyzed (Table 3). To include the factor of TFI as well, we confined the analyses to the 126 patients who showed disease progression after

Table 2 Relationships between pretreatment thrombocytosis and clinicopathologic parameters.

\begin{tabular}{|c|c|c|c|c|}
\hline \multirow[t]{2}{*}{ Parameters } & & \multicolumn{2}{|c|}{ Platelet counts $\left(\times 10^{3} / \mathrm{mm}^{3}\right)$} & \multirow[t]{2}{*}{$P$} \\
\hline & & $<400(n=227)$ & $\geq 400(n=53)$ & \\
\hline Age (years) & Mean \pm SD & $56.8 \pm 11.9$ & $55.9 \pm 11.9$ & 0.52 \\
\hline $\mathrm{Hb}(\mathrm{g} / \mathrm{dl})$ & Mean \pm SD & $12.1 \pm 1.4$ & $10.9 \pm 1.7$ & $<0.0001$ \\
\hline \multicolumn{2}{|c|}{ Microcytic hypochromic anemia } & & & 0.00090 \\
\hline \multicolumn{2}{|l|}{ Present } & $12(5.3 \%)$ & $11(20.8 \%)$ & \\
\hline \multicolumn{2}{|l|}{ Absent } & $215(94.7 \%)$ & 42 (79.2\%) & \\
\hline \multicolumn{2}{|l|}{ Primary treatment } & & & 0.0028 \\
\hline \multicolumn{2}{|l|}{ PDS } & $177(78.0 \%)$ & $30(56.6 \%)$ & \\
\hline \multicolumn{2}{|l|}{ NAC } & $50(22.0 \%)$ & $23(43.4 \%)$ & \\
\hline \multicolumn{2}{|l|}{ FIGO stage } & & & 0.0018 \\
\hline \multicolumn{2}{|l|}{ । } & $82(36.1 \%)$ & $9(17.0 \%)$ & \\
\hline \multicolumn{2}{|l|}{$\|$} & 35 (15.4\%) & $4(7.5 \%)$ & \\
\hline \multicolumn{2}{|l|}{ III } & $84(37.0 \%)$ & $26(49.1 \%)$ & \\
\hline \multicolumn{2}{|l|}{ IV } & $26(11.5 \%)$ & $14(26.4 \%)$ & \\
\hline \multicolumn{2}{|c|}{ Histologic subtype } & & & 0.034 \\
\hline \multicolumn{2}{|l|}{ Serous } & 77 (33.9\%) & $28(52.8 \%)$ & \\
\hline \multicolumn{2}{|l|}{ Clear cell } & $70(30.8 \%)$ & $13(24.5 \%)$ & \\
\hline \multicolumn{2}{|l|}{ Others* } & $80(35.3 \%)$ & $12(22.7 \%)$ & \\
\hline \multicolumn{2}{|c|}{ Operation achievement } & & & 0.00050 \\
\hline \multicolumn{2}{|l|}{ Complete } & $178(78.4 \%)$ & $28(52.8 \%)$ & \\
\hline \multicolumn{2}{|l|}{ Optimal } & $36(15.9 \%)$ & $20(37.7 \%)$ & \\
\hline \multicolumn{2}{|l|}{ Suboptimal } & $13(5.7 \%)$ & $5(9.5 \%)$ & \\
\hline \multicolumn{4}{|c|}{ Nonmalignant inflammatory condition } & 0.0022 \\
\hline Present & & $7(3.1 \%)$ & $8(15.1 \%)$ & \\
\hline Absent & & $220(96.9 \%)$ & $45(84.9 \%)$ & \\
\hline CA125 (U/ mL) & Mean \pm SD & $1233 \pm 3012$ & $3127 \pm 5278$ & $<0.0001$ \\
\hline
\end{tabular}

*Endometorioid, mucinous, undifferentiated, or mixed type. Abbreviations: SD standard deviation, Hb hemoglobin, PDS primary debulking surgery, NAC neoadjuvant chemotherapy, FIGO International Federation of Gynecology and Obstetrics, TFI treatment-free interval 
primary adjuvant chemotherapy. Among the 4 significant factors from the univariate analysis, MHA and TFI were found to be significantly and independently associated with thrombocytosis (Table 3).

Next, we compared PFS and OS according to the presence or absence of thrombocytosis. In all patients, those with thrombocytosis showed significantly poorer PFS (5year PFS rate, $25.2 \%$ vs. $61.8 \%$; Fig. 1a) and OS (5-year OS rate, $41.4 \%$ vs. $75.5 \%$; Fig. 1b) compared to those without thrombocytosis. When the analysis was confined to the patients with stage III/IV disease, thrombocytosis was still significantly associated with poor PFS (5-year PFS rate, $0.0 \%$ vs. $34.0 \%$; Fig. 2a) and OS (5-year OS rate, $26.1 \%$ vs. $56.9 \%$; Fig. $2 \mathrm{~b}$ ), in contrast with the patients with stage I/II disease who showed no difference in PFS (5-year PFS rate, $86.0 \%$ vs. $83.9 \%$; Fig. 2c) or OS (5-year OS rate, $92.0 \%$ vs. $90.1 \%$; Fig. 2 d).

Last, we performed a multivariate analysis of pretreatment thrombocytosis for OS and PFS, adjusted for age, MHA, histologic subtype, FIGO stage, primary treatment, nonmalignant inflammatory condition, and operation achievement (Table 4). Pretreatment thrombocytosis was found to be an independent prognostic factor for poor PFS and OS (Table 4).

\section{Discussion}

We observed pretreatment thrombocytosis, defined as a platelet count $\geq 400,000 / \mathrm{mm}^{3}$, in $18.9 \%$ of the patients with stage I-IV epithelial ovarian cancer, which is in line with previous reports using the same cutoff value as ours $(7.4-42.5 \%)[10-12,15]$. Our analyses of the relationships between thrombocytosis and clinicopathologic parameters showed that thrombocytosis was significantly associated with MHA, primary treatment, FIGO stage, histologic subtype, operation achievement, nonmalignant inflammatory condition, CA125 level, and TFI (Tables 2 and 3). Among these significant factors, FIGO stage, CA125 level, operation achievement, and primary treatment are considered to reflect the tumor extent, which has been reportedly associated with pretreatment thrombocytosis $[6,20]$. MHA and nonmalignant inflammatory condition are clinically well known to induce thrombocytosis. We subsequently conducted univariate and multivariate analyses for associations with thrombocytosis in patients who relapsed after adjuvant chemotherapy, excluding the 2 factors of CA125 level and primary treatment, which are considered to be closely related to FIGO stage. We found that MHA and TFI were significantly and independently associated with thrombocytosis (Table 3). Accordingly, thrombocytosis is suggested to possibly contribute to chemoresistance, as TFI is known to be an important surrogate marker for the chemosensitivity of ovarian cancer [21-23]. Regarding MHA, iron deficiency anemia caused by intratumoral hemorrhage in ovarian cancer is likely to be involved.

Our survival analyses showed that patients with thrombocytosis had worse PFS and OS than those without thrombocytosis (Figs. 1a, b). In addition, when the

Table 3 Univariate and multivariate analyses of risk factors for pretreatment thrombocytosis

\begin{tabular}{|c|c|c|c|c|c|c|}
\hline \multirow[t]{2}{*}{ Factors } & \multicolumn{2}{|c|}{ Platelet counts $\left(\times 10^{3} / \mathrm{mm}^{3}\right)$} & \multicolumn{2}{|l|}{ Univariate } & \multicolumn{2}{|l|}{ Mutivariate } \\
\hline & $<400(n=88)$ & $\geq 400(n=38)$ & OR $(95 \% \mathrm{Cl})$ & $P$ & OR $(95 \% \mathrm{Cl})$ & $P$ \\
\hline \multicolumn{3}{|l|}{ Microcytic hypochromic anemia } & & 0.0022 & & 0.0091 \\
\hline Present & $4(4.6 \%)$ & $7(18.4 \%)$ & $7.56(2.04-36.23)$ & & $6.52(1.57-36.73)$ & \\
\hline Absent & $84(95.4 \%)$ & $31(81.6 \%)$ & Ref & & Ref & \\
\hline \multicolumn{2}{|l|}{ FIGO stage } & & & 0.028 & & 0.15 \\
\hline $\mid / \|$ & $17(19.3 \%)$ & $2(5.3 \%)$ & Ref & & Ref & \\
\hline III/ IV & $71(80.7 \%)$ & $36(94.7 \%)$ & $4.31(1.15-28.12)$ & & $2.84(0.72-18.95)$ & \\
\hline \multicolumn{2}{|l|}{ Histologic subtype } & & & 0.061 & & - \\
\hline Serous & $47(53.4 \%)$ & 27 (71.1\%) & $2.41(0.97-5.00)$ & & - & \\
\hline Others* & $41(46.6 \%)$ & $11(28.9 \%)$ & Ref & & - & \\
\hline \multicolumn{3}{|l|}{ Operation achievement } & & 0.89 & & - \\
\hline Complete, Optimal & 78 (88.6\%) & $34(89.5 \%)$ & Ref & & - & \\
\hline Suboptimal & $10(11.4 \%)$ & $4(10.5 \%)$ & $0.92(0.24-2.96)$ & & - & \\
\hline \multicolumn{3}{|c|}{ Non-malignant inflammatory condition } & & 0.041 & & 0.17 \\
\hline Present & $4(4.6 \%)$ & $6(15.8 \%)$ & $3.94(1.06-16.27)$ & & $2.67(0.085-1.56)$ & \\
\hline Absent & $84(95.4 \%)$ & $32(84.2 \%)$ & Ref & & Ref & \\
\hline TFI (months) & $16.5 \pm 23.03$ & $8.30 \pm 7.31$ & $0.003(0.00-0.30)$ & 0.0091 & $0.0095(0.00-0.75)$ & 0.021 \\
\hline
\end{tabular}

*Endometorioid, mucinous, undifferentiated, or mixed type. Abbreviations: OR odds ratio, $\mathrm{Cl}$ confidence interval, $S D$ standard deviation, $\mathrm{H} b$ hemoglobin, Ref reference, FIGO International Federation of Gynecology and Obstetrics, TFI treatment-free interval 
(A)

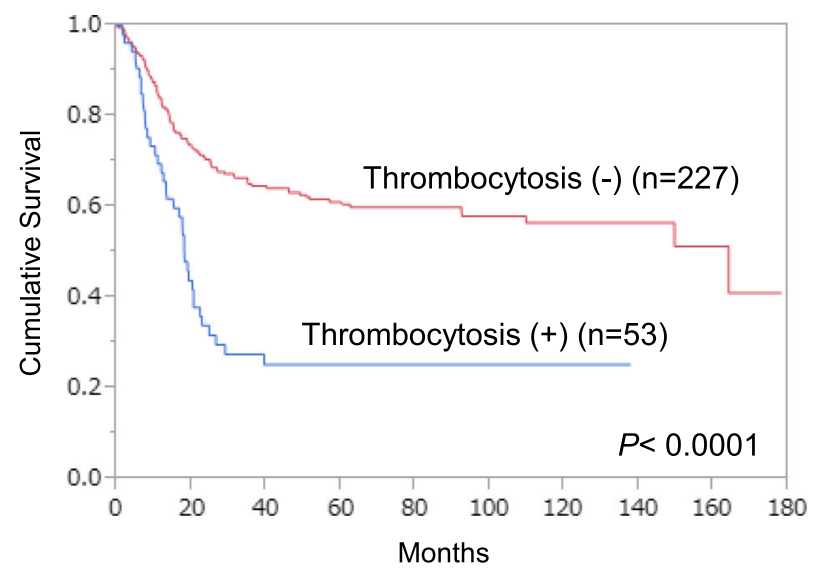

(B)

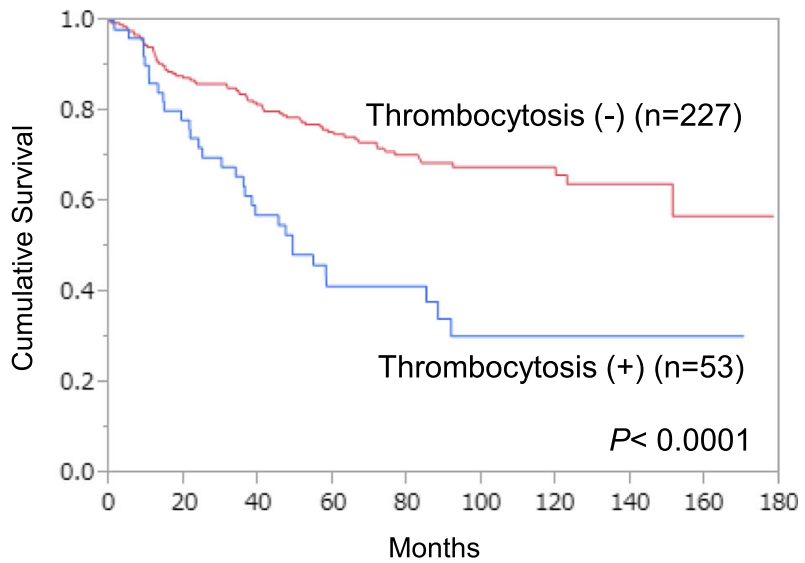

Fig. 1 Survival curves in all patients according to the presence/absence of pretreatment thrombocytosis $(n=280)$. a, PFS in all patients. $\mathbf{b}$, OS in all patients

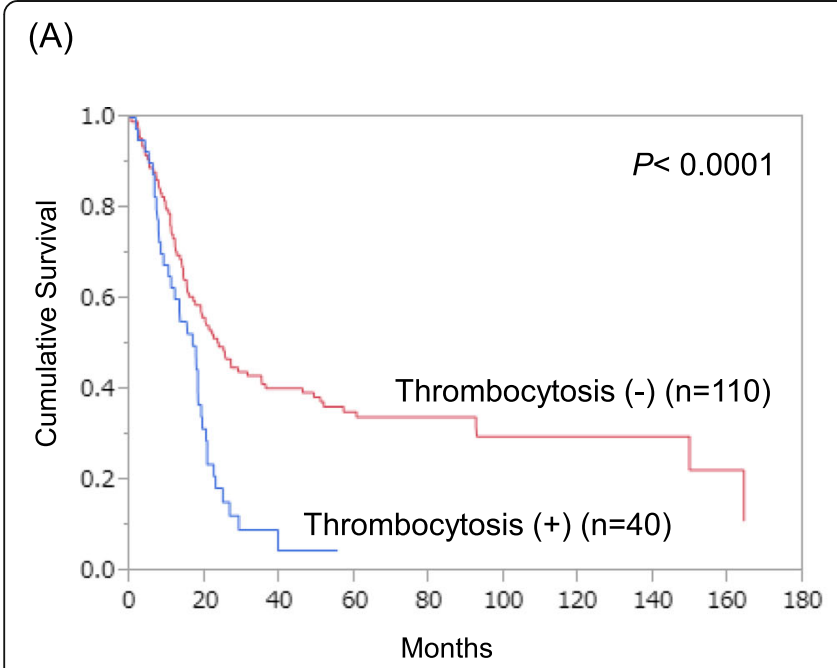

(C)

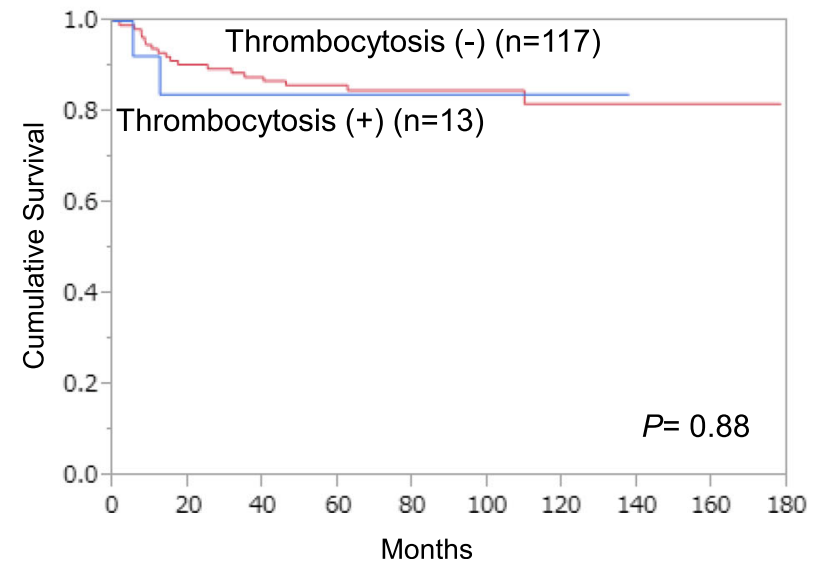

(B)

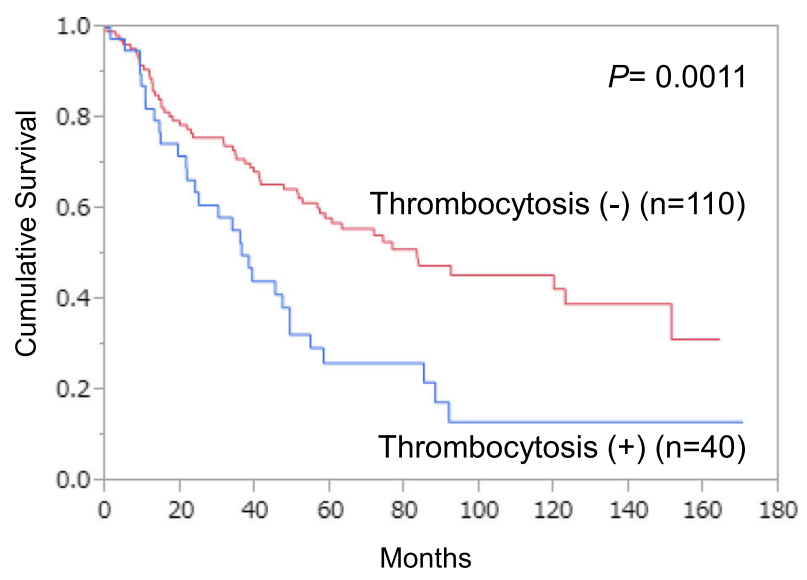

(D)

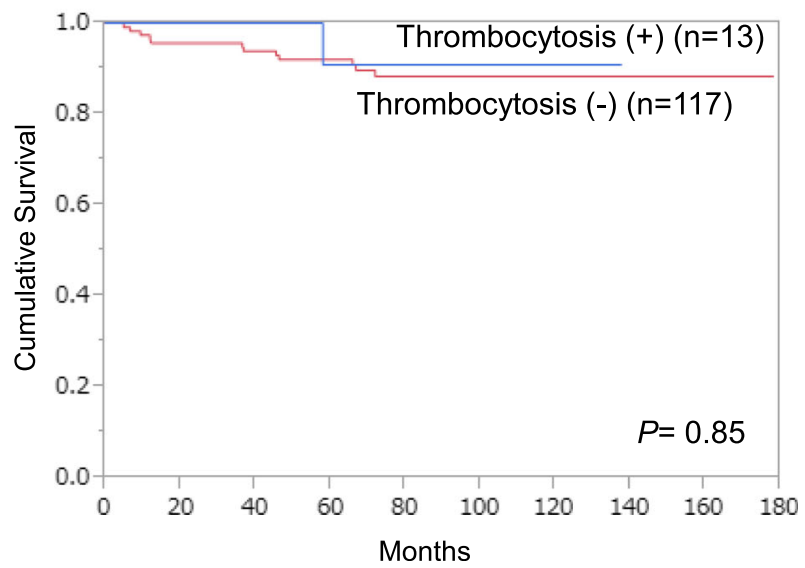

Fig. 2 Survival curves in patients with stage III/IV $(n=150)$ or $I / I I(n=130)$ disease according to the presence/absence of pretreatment thrombocytosis. a, PFS in stage III/IV patients. b, OS in stage III/IV patients. c, PFS in stage I/II patients. D, OS in stage I/II patients 
Table 4 Univariate and multivariate analyses of prognostic factors for PFS and OS

\begin{tabular}{|c|c|c|c|c|c|c|c|c|c|}
\hline \multirow[b]{3}{*}{ Factors } & \multirow{3}{*}{$\begin{array}{l}\text { No. } \\
(n=280)\end{array}$} & \multicolumn{4}{|l|}{ PFS } & \multicolumn{4}{|l|}{ OS } \\
\hline & & \multicolumn{2}{|l|}{ Univariate } & \multicolumn{2}{|l|}{ Multivariate } & \multicolumn{2}{|l|}{ Univariate } & \multicolumn{2}{|l|}{ Multivariate } \\
\hline & & $\mathrm{HR}(95 \% \mathrm{Cl})$ & $P$ & Adjusted HR (95\% CI) & $P$ & $\mathrm{HR}(95 \% \mathrm{Cl})$ & $P$ & Adjusted HR (95\% Cl) & $P$ \\
\hline Age (years) & & & 0.035 & & 0.19 & & 0.014 & & 0.072 \\
\hline$<50$ & 77 & Ref & & Ref & & Ref & & Ref & \\
\hline$\geq 50$ & 203 & $\begin{array}{l}1.53(1.03- \\
2.34)\end{array}$ & & $1.32(0.87-2.07)$ & & $1.80(1.12-3.03)$ & & $1.59(0.96-2.74)$ & \\
\hline Platelet counts $\left(\times 10^{3} / \mathrm{mm}^{3}\right)$ & & & $\begin{array}{l}< \\
0.0001\end{array}$ & & 0.0050 & & $\begin{array}{l}< \\
0.0001\end{array}$ & & 0.022 \\
\hline$<400$ & 227 & Ref & & Ref & & Ref & & Ref & \\
\hline$\geq 400$ & 53 & $\begin{array}{l}2.61(1.76- \\
3.80)\end{array}$ & & $1.89(1.22-2.87)$ & & $2.67(1.72-4.06)$ & & $1.79(1.09-2.86)$ & \\
\hline Microcytic hypochromic anemia & & & 0.62 & & 0.30 & & 0.44 & & 0.15 \\
\hline Present & 8 & $\begin{array}{l}1.17(0.59- \\
2.07)\end{array}$ & & $1.43(0.71-2.36)$ & & $1.33(0.62-2.49)$ & & $1.75(0.80-3.42)$ & \\
\hline Absent & 272 & Ref & & Ref & & Ref & & Ref & \\
\hline Histologic subtype & & & $\begin{array}{l}< \\
0.0001\end{array}$ & & 0.67 & & $\begin{array}{l}< \\
0.0001\end{array}$ & & 0.21 \\
\hline Serous & 105 & Ref & & Ref & & Ref & & Ref & \\
\hline Non-serous & 175 & $\begin{array}{l}0.36(0.25- \\
0.51)\end{array}$ & & $0.92(0.62-1.35)$ & & $0.45(0.30-0.67)$ & & $1.33(0.85-2.05)$ & \\
\hline FIGO stage & & & $\begin{array}{l}< \\
0.0001\end{array}$ & & $\begin{array}{l}< \\
0.0001\end{array}$ & & $\begin{array}{l}< \\
0.0001\end{array}$ & & $\begin{array}{l}< \\
0.0001\end{array}$ \\
\hline$|/| \mid$ & 130 & Ref & & Ref & & Ref & & Ref & \\
\hline III/ IV & 150 & $\begin{array}{l}7.80(4.94- \\
13.0)\end{array}$ & & $5.47(3.18-9.69)$ & & $\begin{array}{l}7.92(4.58- \\
14.91)\end{array}$ & & $6.26(3.30-12.57)$ & \\
\hline Primary treatment & & & $\begin{array}{l}< \\
0.0001\end{array}$ & & 0.018 & & $\begin{array}{l}< \\
0.0001\end{array}$ & & 0.0052 \\
\hline PDS & 207 & Ref & & Ref & & Ref & & Ref & \\
\hline NAC & 73 & $\begin{array}{l}2.99(2.09- \\
4.26)\end{array}$ & & $1.60(1.09-2.35)$ & & $3.29(2.18-4.95)$ & & $1.90(1.21-2.98)$ & \\
\hline $\begin{array}{l}\text { Nonmalignant inflammatory } \\
\text { condition }\end{array}$ & & & 0.061 & & 0.55 & & 0.0053 & & 0.24 \\
\hline Absent & 265 & Ref & & Ref & & Ref & & Ref & \\
\hline Present & 15 & $\begin{array}{l}1.97(0.97- \\
3.57)\end{array}$ & & $0.81(0.38-1.56)$ & & $2.92(1.42-5.35)$ & & $0.64(0.33-1.37)$ & \\
\hline Operation achievement & & & $\begin{array}{l}< \\
0.0001\end{array}$ & & $\begin{array}{l}< \\
0.0001\end{array}$ & & $\begin{array}{l}< \\
0.0001\end{array}$ & & $\begin{array}{l}< \\
0.0001\end{array}$ \\
\hline Complete, Optimal & 262 & Ref & & Ref & & Ref & & Ref & \\
\hline Suboptimal & 18 & $\begin{array}{l}7.31(4.18- \\
12.0)\end{array}$ & & $4.41(2.46-7.48)$ & & $6.40(3.46-11.0)$ & & $4.60(2.41-8.24)$ & \\
\hline
\end{tabular}

Abbreviations: PFS progression-free survival, OS overall survival, HR hazard ratio, CI confidence interval, Ref reference, FIGO International Federation of Gynecology and Obstetrics, PDS primary debulking surgery, NAC neoadjuvant chemotherapy

analysis was confined to stage III/IV patients, there was still a significant difference in PFS and OS (Figs. 2a, b), whereas stage I/II patients showed no difference in survival according to the presence/absence of pretreatment thrombocytosis (Figs. 2c, d). These findings indicate that thrombocytosis affects survival mainly in advanced diseases, consistent with our above finding that thrombocytosis was significantly and independently associated with TFI, an established predictor of chemosensitivity in the treatment of recurrence, as recurrence is prone to occur in advanced diseases. Furthermore, our multivariate analysis for prognostic factors demonstrated that thrombocytosis was significant for unfavorable PFS and OS independent of age, histology, and FIGO stage (Table 4). These findings indicate that pretreatment thrombocytosis may be an ideal predictive biomarker for treatment outcome and a reasonable therapeutic target in epithelial ovarian cancer.

Tumor cells first increase and activate platelets via various cytokines, including interleukin-6 (IL-6, 16). Activated platelets in turn facilitate tumor growth and angiogenesis through growth factors and angiogenic 
factors, including VEGF and PDGF [16, 24]. Activated platelets also promote metastasis through epithelial mesenchymal transition (EMT) and defense by platelettumor interactions against blood flow and the immune system, including NK cells, in circulation [16, 24]. In addition, platelets contribute to chemoresistance through MAPK and PI3-kinase/Akt pathways and drug efflux proteins [24]. Moreover, chemoresistance in ovarian cancer cells is suggested to involve the interaction between the surrounding immune system and cancer stem cells in the tumor microenvironment, where platelets play key roles $[25,26]$. Therefore, thrombocytosis can possibly affect patient prognosis via both tumor progression and chemoresistance. However, we found that thrombocytosis was significantly and independently associated with TFI but not with FIGO stage (Table 3) and that thrombocytosis was significantly associated with PFS independent of FIGO stage (Table 4). These findings suggest that the prognostic impact of thrombocytosis may be independent of tumor extent but rather attributed to chemoresistance. Indeed, platelets have been reported to be involved in chemoresistance in ovarian cancer by in vitro and in vivo basic studies. Radziwon-Balicka et al. reported that platelets decreased paclitaxel-induced apoptosis in human ovarian adenocarcinoma cells in vitro [27]. Bottsford-Miller et al. reported that the combined administration of plateletdepleting antibodies and docetaxel caused a $62 \%$ decrease in tumor weight compared to docetaxel treatment in orthotopic mouse models of human ovarian cancer [6]. They further found that platelet transfusion blocked the effect of docetaxel on tumor growth, and aspirinization blocked the effect of transfusion. However, clinical evidence suggesting the link between thrombocytosis and chemoresistance in ovarian cancer is very limited, as most studies only correlate thrombocytosis with survival after chemotherapy. Bottsford-Miller et al. reported changes in platelet counts during first-line chemotherapy in responsive and refractory groups matched for stage, histology, grade, and primary therapy [28]. In patients with a durable response, only $50 \%$ had pretreatment thrombocytosis, and all of them achieved a normal platelet count during therapy, whereas all had pretreatment thrombocytosis, and only 50\% achieved a normal count during therapy in patients with refractory disease. However, the possibility that platelet count only reflects the real-time residual tumor amount cannot be excluded. Feng et al. reported that preoperative thrombocytosis was significantly associated with chemoresistance determined based on the interval between disease progression and adjuvant chemotherapy in high-grade serous ovarian cancer [20]. However, thrombocytosis was not significant after stratification based on residual tumors after surgery. In our study, pretreatment thrombocytosis was not associated with operation achievement and was significantly associated with TFI independent of FIGO stage (Table 3). Moreover, pretreatment thrombocytosis was a significant prognostic factor for poor PFS and OS independent of FIGO stage and operation achievement (Table 4). These observations strongly support the involvement of thrombocytosis in chemoresistance, implicating that molecular therapy targeting thrombocytosis may improve prognosis by attenuating chemoresistance. Based on the current findings, we assume that the combination of chemotherapeutics and antiplatelet therapies may be efficacious for ovarian cancer patients with thrombocytosis. Notably, patients with MHA or nonmalignant inflammatory conditions may have to be excluded from the treatment subjects, as the pathways for thrombocytosis in these patients must be different from those for paraneoplastic thrombocytosis.

Stone et al. proposed that increased hepatic thrombopoietin synthesis in response to tumor-derived IL- 6 was a mechanism for paraneoplastic thrombocytosis [29]. They further reported that treatment with siltuximab, an anti-IL-6 antibody, significantly enhanced the therapeutic efficacy of paclitaxel in mouse models of epithelial ovarian cancer. Regarding clinical trials, a phase II study in patients with platinum-resistant ovarian cancer reported that siltuximab treatment showed a partial response in one patient and disease stabilization in 7 of 18 of the evaluated patients [30]. Regarding the combination with chemotherapeutics, a phase I trial in patients with recurrent epithelial ovarian cancer reported that the combination of carboplatin/doxorubicin and tocilizumab, an anti-IL- 6 receptor antibody, and interferon$\alpha 2 b$ showed complete response in 3, partial response in 8 , and stable disease in 6 of the 21 evaluated patients, and they showed that the toxicity was tolerable [31]. Additional clinical trials and the examination of clinical samples are warranted to evaluate the usefulness and to investigate the underlying mechanism of anti-IL- 6 therapies in ovarian cancer.

Our study has the following limitations. First, the sample size of the subset analyses was relatively small. Second, the strengthening of our hypothesis by basic study data was lacking. Third, the retrospective study design potentially caused selection biases. Prospective studies are required to verify our findings.

\section{Conclusions}

We reported here on the precise prognostic impact of pretreatment thrombocytosis in epithelial ovarian cancer. Univariate and multivariate analyses revealed that thrombocytosis was independently associated with TFI and MHA. Thrombocytosis was correlated with poor OS and PFS in advanced stages but showed no difference in 
early stages of disease. The multivariate analysis for prognostic factors demonstrated that thrombocytosis was significant for OS and PFS independent of stage, histology, primary treatment, operation achievement, nonmalignant inflammatory condition, and MHA. The current findings implicate that the unfavorable prognostic impact of thrombocytosis may be ascribed to chemoresistance, further supporting the therapeutic potential of targeting thrombopoietic cytokines in epithelial ovarian cancer.

\section{Abbreviations}

FIGO: International Federation of Gynecology and Obstetrics; IDS: Interval debulking surgery.; MHA: Microcytic hypochromic anemia.; NAC: Neoadjuvant chemotherapy.; OS: Overall survival.; PDS: Primary debulking surgery.; PFS: Progression-free survival.; TC: Paclitaxel and carboplatin.; TFI: Treatmentfree interval.

\section{Acknowledgements}

Not applicable.

\section{Authors' contributions}

SN and KM contributed to the conception and design; SN analyzed the data and drafted the manuscript; TM revised the manuscript; $H I, Y H, A S, N T, A A$, $\mathrm{HO}, \mathrm{KM}$ and TS critically reviewed the manuscript; SN, TM, HI, YH, AS, NT, AA, $\mathrm{HO}, \mathrm{KM}$ and TS treated the patients; and TS supervised the study. All authors read and approved the final manuscript.

\section{Funding}

Not applicable.

\section{Availability of data and materials}

The datasets used and/or analyzed during the current study are available from the corresponding author upon reasonable request.

\section{Ethics approval and consent to participate}

The present study was conducted in accordance with the Declaration of Helsinki. The study protocol was approved by the Ethics Committee University of Tsukuba Hospital (H27-143) with a waiver of informed consent.

\section{Consent for publication}

Not applicable.

\section{Competing interests}

The authors declare that they have no competing interests.

\section{Author details}

${ }^{1}$ Department of Obstetrics and Gynecology, Faculty of Medicine, University of Tsukuba, 1-1-1 Tennoudai, Tsukuba, Ibaraki 305-8575, Japan. ${ }^{2}$ Department of Obstetrics and Gynecology, Showa University School of Medicine, Tokyo, Japan.

Received: 20 February 2020 Accepted: 16 April 2020

Published online: 06 May 2020

\section{References}

1. Heintz AP, Odicino F, Maisonneuve P, Quinn MA, Benedet JL, Creasman WT, et al. Carcinoma of the ovary. FIGO 26th Annual Report on the Results of Treatment in Gynecological Cancer. Int J Gynaecol Obstet, Suppl 1. 2006;95: S161-92

2. Winter WE 3rd, Maxwell GL, Tian C, Sundborg MJ, Rose GS, Rose PG, et al. Tumor residual after surgical cytoreduction in prediction of clinical outcome in stage IV epithelial ovarian cancer: a gynecologic oncology group study. J Clin Oncol. 2008:26(1):83-9.

3. Winter WE 3rd, Maxwell GL, Tian C, Carlson JW, Ozols RF, Rose PG, et al. Prognostic factors for stage III epithelial ovarian cancer: a gynecologic oncology group study. J Clin Oncol. 2007;25(24):3621-7.
4. Eisenhauer EL, Abu-Rustum NR, Sonoda Y, Aghajanian C, Barakat RR, Chi DS. The effect of maximal surgical cytoreduction on sensitivity to platinumtaxane chemotherapy and subsequent survival in patients with advanced ovarian cancer. Gynecol Oncol. 2008;108(2):276-81.

5. Chi DS, Eisenhauer EL, Lang J, Huh J, Haddad L, Abu-Rustum NR, et al. What is the optimal goal of primary cytoreductive surgery for bulky stage IIIC epithelial ovarian carcinoma (EOC)? Gynecol Oncol. 2006;103(2):559-64.

6. Allensworth SK, Langstraat CL, Martin JR, Lemens MA, McGree ME, Weaver $\mathrm{AL}$, et al. Evaluating the prognostic significance of preoperative thrombocytosis in epithelial ovarian cancer. Gynecol Oncol. 2013;130(3): 499-504.

7. Cohen JG, Tran AQ, Rimel BJ, Cass I, Walsh CS, Karlan BY, et al. Thrombocytosis at secondary cytoreduction for recurrent ovarian cancer predicts suboptimal resection and poor survival. Gynecol Oncol. 2014;132(3):556-9.

8. Menczer J. Preoperative elevated platelet count and thrombocytosis in gynecologic malignancies. Arch Gynecol Obstet. 2017;295(1):9-15.

9. Digklia A, Voutsadakis IA. Thrombocytosis as a prognostic marker in stage III and IV serous ovarian cancer. Obstet Gynecol Sci. 2014;57(6):457-63.

10. Chen Y, Zhang L, Liu W-X, Liu X-Y. Prognostic significance of preoperative anemia, leukocytosis and thrombocytosis in chinese women with epithelial ovarian cancer. Asian Pac J Cancer Prev. 2015;16(3):933-9.

11. Cozzi GD, Samuel JM, Fromal JT, Keene S, Crispens MA, Khabele D, et al. Thresholds and timing of pre-operative thrombocytosis and ovarian cancer survival: analysis of laboratory measures from electronic medical records. BMC Cancer. 2016;16:612.

12. Gungor T, Kanat-Pektas M, Sucak A, Mollamahmutoglu L. The role of thrombocytosis in prognostic evaluation of epithelial ovarian tumors. Arch Gynecol Obstet. 2009;279(1):53-6.

13. Lee M, Kim SW, Nam EJ, Yim GW, Kim S, Kim YT. The impact of pretreatment thrombocytosis and persistent thrombocytosis after adjuvant chemotherapy in patients with advanced epithelial ovarian cancer. Gynecol Oncol. 2011;122(2):238-41.

14. Li AJ, Madden AC, Cass I, Leuchter RS, Lagasse LD, Karlan BY. The prognostic significance of thrombocytosis in epithelial ovarian carcinoma. Gynecol Oncol. 2004;92(1):211-4

15. Qiu J, Yu Y, Fu Y, Ye F, Xie X, Lu W. Preoperative plasma fibrinogen, platelet count and prognosis in epithelial ovarian cancer. J Obstet Gynaecol Res. 2012;38(4):651-7.

16. Buergy D, Wenz F, Groden C, Brockmann MA. Tumor-platelet interaction in solid tumors. Int J Cancer. 2012;130(12):2747-60.

17. Dijkgraaf E, Santegoets S, Reyners A, Goedemans R, Wouters M, Kenter G, et al. A phase I trial combining carboplatin/doxorubicin with tocilizumab, an anti-IL-6R monoclonal antibody, and interferon- $a 2 b$ in patients with recurrent epithelial ovarian cancer. Ann Oncol. 2015;26(10):2141-9.

18. Angevin E, Tabernero J, Elez E, Cohen SJ, Bahleda R, Van Laethem J-L, et al. A phase I/II, multiple-dose, dose-escalation study of siltuximab, an antiinterleukin-6 monoclonal antibody, in patients with advanced solid tumors. Clin Cancer Res. 2014;20(8):2192-204

19. Satoh T, Oki A, Uno K, Sakurai M, Ochi H, Okada S, et al. High incidence of silent venous thromboembolism before treatment in ovarian cancer. $\mathrm{Br}$ J Cancer. 2007:97(8):1053-7.

20. Feng Z, Wen H, Bi R, Duan Y, Yang W, Wu X. Thrombocytosis and hyperfibrinogenemia are predictive factors of clinical outcomes in highgrade serous ovarian cancer patients. BMC Cancer. 2016;16:43.

21. Colombo N, Gore M. Treatment of recurrent ovarian cancer relapsing 6-12 months post platinum-based chemotherapy. Crit Rev Oncol Hematol. 2007; 64(2):129-38.

22. Markman M, Rothman R, Hakes T, Reichman B, Hoskins W, Rubin S, et al. Second-line platinum therapy in patients with ovarian cancer previously treated with cisplatin. J Clin Oncol. 1991:9(3):389-93.

23. Harries M, Gore M. Part II: Chemotherapy for epithelial ovarian cancertreatment of rcurrent disease. Lancet Oncol. 2002:3(9):537-45.

24. Huong PT, Nguyen LT, Nguyen XB, Lee SK, Bach DH. The Role of Platelets in the Tumor-Microenvironment and the Drug Resistance of Cancer Cells. Cancers (Basel). 2019;11(2)

25. Lagana AS, Sofo V Vitale SG, Triolo O. Epithelial ovarian cancer inherent resistance: may the pleiotropic interaction between reduced immunosurveillance and drug-resistant cells play a key role? Gynecol Oncol Rep. 2016;18:57-8.

26. Chiu WT, Huang YF, Tsai HY, Chen CC, Chang CH, Huang SC, et al. FOXM1 confers to epithelial-mesenchymal transition, stemness and 
chemoresistance in epithelial ovarian carcinoma cells. Oncotarget. 2015;6(4): 2349-65.

27. Radziwon-Balicka A, Medina C, O'Driscoll L, Treumann A, Bazou D, Inkielewicz-Stepniak I, et al. Platelets increase survival of adenocarcinoma cells challenged with anticancer drugs: mechanisms and implications for chemoresistance. Br J Pharmacol. 2012;167(4):787-804.

28. Bottsford-Miller J, Choi HJ, Dalton HJ, Stone RL, Cho MS, Haemmerle M, et al. Differential platelet levels affect response to taxane-based therapy in ovarian cancer. Clin Cancer Res. 2015;21(3):602-10.

29. Stone RL, Nick AM, McNeish IA, Balkwill F, Han HD, Bottsford-Miller J, et al. Paraneoplastic thrombocytosis in ovarian cancer. N Engl J Med. 2012;366(7): 610-8.

30. Coward J, Kulbe H, Chakravarty P, Leader D, Vassileva V, Leinster DA, et al. Interleukin-6 as a therapeutic target in human ovarian cancer. Clin Cancer Res. 2011:17(18):6083-96.

31. Dijkgraaf EM, Santegoets SJ, Reyners AK, Goedemans R, Wouters MC, Kenter $\mathrm{GG}$, et al. A phase I trial combining carboplatin/doxorubicin with tocilizumab, an anti-IL-6R monoclonal antibody, and interferon-alpha2b in patients with recurrent epithelial ovarian cancer. Ann Oncol. 2015;26(10): 2141-9.

\section{Publisher's Note}

Springer Nature remains neutral with regard to jurisdictional claims in published maps and institutional affiliations.

Ready to submit your research? Choose BMC and benefit from:

- fast, convenient online submission

- thorough peer review by experienced researchers in your field

- rapid publication on acceptance

- support for research data, including large and complex data types

- gold Open Access which fosters wider collaboration and increased citations

- maximum visibility for your research: over $100 \mathrm{M}$ website views per year

At BMC, research is always in progress.

Learn more biomedcentral.com/submissions 